\title{
Conversion of Polyolefin Waste to Liquid Alkanes with Ru-Based Catalysts under Mild Conditions
}

\author{
Julie E. Rorrer, ${ }^{[\mathrm{a}]}$ Gregg T. Beckham, ${ }^{[\mathrm{b}]}$ Yuriy Román-Leshkov ${ }^{[\mathrm{a}] *}$ \\ [a] Department of Chemical Engineering, Massachusetts Institute of Technology, 77 Massachusetts Ave, Cambridge, MA \\ 02139, USA, [b] Renewable Resources and Enabling Sciences Center, National Renewable Energy Laboratory, Golden, CO,
} USA.

Supporting Information

\begin{abstract}
Chemical upcycling of waste polyolefins via hydrogenolysis offers unique opportunities for selective depolymerization compared to high temperature thermal deconstruction. Here, we demonstrate the hydrogenolysis of polyethylene into liquid alkanes under mild conditions using ruthenium nanoparticles supported on carbon $(\mathrm{Ru} / \mathrm{C})$. Reactivity studies on a model $n$-octadecane substrate showed that $\mathrm{Ru} / \mathrm{C}$ catalysts are highly active and selective for the hydrogenolysis of $\mathrm{C}\left(\mathrm{sp}^{3}\right)-\mathrm{C}\left(\mathrm{sp}^{3}\right)$ bonds at temperatures ranging from $200-250^{\circ} \mathrm{C}$. Under optimal conditions of $200^{\circ} \mathrm{C}$ in 20 bar $\mathrm{H}_{2}$, polyethylene (average $\mathrm{M}_{\mathrm{w}} \sim 4,000$ ) was converted into liquid $n$-alkanes with yields of up to $45 \%$ by mass after $16 \mathrm{~h}$ using a $5 \mathrm{wt} \% \mathrm{Ru} / \mathrm{C}$ catalyst, with the remaining products comprising light alkane gases $\left(\mathrm{C}_{1}-\mathrm{C}_{6}\right)$. At $250^{\circ} \mathrm{C}$, nearly stoichiometric yields of $\mathrm{CH}_{4}$ were obtained from polyethylene over the catalyst. The hydrogenolysis of long chain, low-density polyethylene (LDPE) and a post-consumer LDPE plastic bottle to produce $\mathrm{C}_{7}-\mathrm{C}_{45}$ alkanes was also achieved over $\mathrm{Ru} / \mathrm{C}$, demonstrating the feasibility of this reaction for the valorization of realistic post-consumer plastic waste. By identifying Ru-based catalysts as a class of active materials for the hydrogenolysis of polyethene, this study opens new avenues for the valorization of plastic waste under mild conditions.
\end{abstract}

The development of polyolefins has enabled the production of safe and sturdy single-use plastic packaging for transportation and storage, sterile medical devices, and countless other transformative consumer products. Because the raw materials for producing polyolefins such as polyethylene (PE) and polypropylene (PP) are abundant and inexpensive, the manufacture of these plastics is immense, and continues to grow. Worldwide, approximately 380 million tons of plastics are generated annually, $57 \%$ percent of which are polyolefins. ${ }^{1}$ Projections estimate that by 2050 , plastic production will reach over 1.1 billion tons per year. ${ }^{2}$ From a chemistry perspective, the strong $\mathrm{sp}^{3}$ carbon-carbon bonds in polyolefins that provide desirable material properties also make them highly recalcitrant to degradation. Mechanical recycling is one method of utilizing plastic waste; however, only around $16 \%$ of plastic is actually recycled, ${ }^{3}$ and usually ends up being "downcycled" into lower-value materials with diminished properties. ${ }^{4}$ The majority of single-use plastics end up in landfills or the environment, harming the ecosystem and effecting the natural enviornment. ${ }^{1,3,5}$

Thermochemical pathways, such as pyrolysis and thermal cracking, enable polyolefin depolymerization by breaking the strong $\mathrm{C}-\mathrm{C}$ bonds in $\mathrm{PE}$ to produce small molecules that could be used as fuel or integrated into chemical refineries. However, these processes are energy intensive and suffer from low control over product selectivity., 6,8 Alternatively, $\mathrm{C}-\mathrm{C}$ bond cleavage via hydrogenolysis allows for selective depolymerization of polyolefins into liquid alkanes with targeted molecular weight ranges. This reaction has been studied in the context of short-chain alkane ${ }^{9-14}$ and lignin ${ }^{15-16}$ conversion, but has not been extensively explored for the depolymerization of polyolefins with high molecular weights. Dufaud and Basset studied the degradation of model PE $\left(\mathrm{C}_{20}-\mathrm{C}_{50}\right)$ and $\mathrm{PP}$ over a zirconium hydride supported on silica-alumina, and found moderate activity under mild conditions (190 $\left.{ }^{\circ} \mathrm{C}\right) .{ }^{17}$ Celik et al. investigated hydrogenolysis using well-dispersed Pt nanoparticles supported on $\mathrm{SrTiO}_{3}$ nanocuboids for the depolymerization of PE $\left(\mathrm{M}_{\mathrm{n}}=8,000-158,000 \mathrm{Da}\right)$ at $170 \mathrm{psi}_{2}$ and $300^{\circ} \mathrm{C}$ for $96 \mathrm{~h}$ under solvent free conditions, obtaining high yields of liquid hydrocarbons. ${ }^{18}$ The authors argued that this catalyst is superior to $\mathrm{Pt} / \mathrm{Al}_{2} \mathrm{O}_{3}$ because it produced fewer light hydrocarbons and promoted favorable adsorption of PE on Pt sites. Open questions remain whether the higher yield of light hydrocarbons over $\mathrm{Pt} / \mathrm{Al}_{2} \mathrm{O}_{3}$ was due to the acidity of the support, a promotional effect of the isomerization and hydrocracking pathways, or increased activity for terminal $\mathrm{C}-\mathrm{C}$ bond cleavage, and whether similar activity could be obtained at lower temperatures. Indeed, further investigation of other supported noble metals for hydrogenolysis at even milder conditions is needed.

Here we demonstrate the selective depolymerization of polyethylene to processible liquid hydrocarbons under mild conditions in the absence of solvent using Ru nanoparticles supported on carbon. First, we screened a series of noble metal catalysts using $n$ octadecane - a model compound for linear polyethylene-and identified Ru nanoparticles supported on carbon as the most active. Next, we investigated the $\mathrm{C}-\mathrm{C}$ bond cleavage selectivity as a function of conversion to understand how product distributions change as a function of extent of reaction. We then implemented optimized reaction conditions for the hydrogenolysis of a model PE substrate (average $M_{w}$ 4,000) and commercial low-density polyethylene (LDPE). Finally, we demonstrated that the $\mathrm{Ru} / \mathrm{C}$ catalyst is capable of converting LDPE from a real post-consumer plastic bottle. The identification of Ru-based catalysts as a class of materials for highly active hydrogenolysis is important for developing effective depolymerization processes of waste plastics to produce processible and transportable liquid that could be used as fuels, chemicals, or synthons for the next generation of infinitely recyclable polymers. ${ }^{19}$

Ruthenium-based catalysts, such as $\mathrm{Ru} / \mathrm{CeO}_{2}, \mathrm{Ru} / \mathrm{SiO}_{2}$, $\mathrm{Ru} / \mathrm{Al}_{2} \mathrm{O}_{3}$, and $\mathrm{Ru} / \mathrm{TiO}_{2}$, have been shown to be active both for the hydrogenolysis of light alkanes ${ }^{9-14}$ and lignin..$^{20-21}$ Our group has also shown that cobalt-based catalysts have tunable activity for $\mathrm{C}$ $\mathrm{O}$ vs. C-C bond hydrogenolysis of oxygenated arenes. ${ }^{22}$ These 
Table 1: Hydrogenolysis of $n$-octadecane using heterogeneous transition metal catalysts. Reaction conditions: $700 \mathrm{mg} n$-octadecane, $14 \mathrm{~h}, 30$ bar $\mathrm{H}_{2}$ (entries 1, 10), 50 bar $\mathrm{H}_{2}$ (entries 2-9, 11-12)

\begin{tabular}{|l|l|c|c|c|l|l|}
\hline Entry & \multicolumn{1}{|c|}{ Catalyst } & $\begin{array}{c}\text { Temp } \\
{\left[{ }^{\circ} \mathrm{C}\right]}\end{array}$ & $\begin{array}{c}\text { Mass Catalyst } \\
{[\mathrm{mg}]}\end{array}$ & $\begin{array}{c}\text { Conversion, } \\
\mathrm{C}_{18}[\mathrm{~mol} \%]\end{array}$ & Products (Liquid) & \multicolumn{1}{|l|}{ Products (Gaseous) } \\
\hline 1 & $\mathrm{Co}_{3} \mathrm{O}_{4}$ & 200 & 104 & 0 & none & none \\
\hline 2 & $\mathrm{Co}_{3} \mathrm{O}_{4}$ & 250 & 109 & 46 & $n$-alkanes $\left(\mathrm{C}_{14}-\mathrm{C}_{17}\right)$ & $\mathrm{n} / \mathrm{a}$ \\
\hline 3 & $\gamma-\mathrm{Al}_{2} \mathrm{O}_{3}$ & 250 & 103 & 0 & none & none \\
\hline 4 & $1 \% \mathrm{Pt} / \gamma-\mathrm{Al}_{2} \mathrm{O}_{3}$ & 250 & 47.0 & 0 & none & none \\
\hline 5 & $\mathrm{RuO}_{2}$ & 250 & 43.0 & 100 & none & $\mathrm{CH}_{4}$ \\
\hline 6 & $\mathrm{RuO}_{2}$ & 200 & 20.4 & 9 & $n$-alkanes $\left(\mathrm{C}_{9}-\mathrm{C}_{17}\right)$ & $\mathrm{CH}_{4}$ \\
\hline 7 & $5 \% \mathrm{Ru} / \mathrm{Al}_{2} \mathrm{O}_{3}$ & 200 & 26.7 & 65 & $n$-alkanes $\left(\mathrm{C}_{8}-\mathrm{C}_{17}\right)$ & light alkanes $\left(\mathrm{C}_{1}-\mathrm{C}_{4}\right)$ \\
\hline 8 & $5 \% \mathrm{Ru} / \mathrm{Al}_{2} \mathrm{O}_{3}$ & 250 & 26.3 & 100 & none & light alkanes $\left(\mathrm{C}_{1}-\mathrm{C}_{4}\right)$ \\
\hline 9 & $5 \% \mathrm{Rh} / \mathrm{C}$ & 250 & 22.6 & 21 & $n$-alkanes $\left(\mathrm{C}_{8}-\mathrm{C}_{17}\right)$ & light alkanes $\left(\mathrm{C}_{1}-\mathrm{C}_{6}\right)$ \\
\hline 10 & $5 \% \mathrm{Ru} / \mathrm{C}$ & 200 & 25.0 & 92 & $n$-alkanes $\left(\mathrm{C}_{6}-\mathrm{C}_{17}\right)$ & light alkanes $\left(\mathrm{C}_{1}-\mathrm{C}_{5}\right)$ \\
\hline 11 & $5 \% \mathrm{Ru} / \mathrm{C}$ & 250 & 25.0 & 100 & none & $\mathrm{CH}_{4}$ \\
\hline 12 & $\mathrm{NiO}$ & 250 & 25.0 & 0 & none & none \\
\hline
\end{tabular}

previous observations prompted us to test a series of noble metal catalysts including $\mathrm{Ru}-$ and Co-based catalysts, as well as other transition metals, for the hydrogenolysis of $n$-octadecane in $25 \mathrm{~mL}$ Parr stainless steel pressurized reaction vessels under temperatures and $\mathrm{H}_{2}$ pressures ranging from $200-300^{\circ} \mathrm{C}$ and $30-50$ bar, respectively (see Table 1). Products were identified by gas chromatography mass spectrometry (GC-MS), and quantified by GC equipped with a flame ionization detector (FID) and thermal conductivity detector (TCD). Additional methods, catalyst characterization, and product characterization are provided in the Supporting Information (Figures S1-S3, Tables S1-S3). At $250^{\circ} \mathrm{C}, 1 \% \mathrm{Pt} / \gamma-\mathrm{Al}_{2} \mathrm{O}_{3}$, $\mathrm{NiO}$, and $\gamma-\mathrm{Al}_{2} \mathrm{O}_{3}$ were all inactive. Co-based catalysts (entries 12) and Rh-based catalysts (entry 9) showed moderate hydrogenolysis activity, converting $n$-octadecane into a range of $\mathrm{C}_{1}-\mathrm{C}_{17}$ alkanes. Notably, Ru-based catalysts stood out for their high hydrogenolysis activity (entries 5-8,10-11). Specifically, the $5 \mathrm{wt} \% \mathrm{Ru} / \mathrm{C}$ catalyst (entry 10 ) reached an $n$-octadecane conversion of $92 \%$ at $200^{\circ} \mathrm{C}$, generating a mixture of liquid and gaseous alkanes, while at $250^{\circ} \mathrm{C}, 100 \%$ of the $n$-octadecane was converted into $\mathrm{CH}_{4}$. Due to the high activity at low temperatures and relatively low catalyst loadings, the $5 \mathrm{wt} \% \mathrm{Ru} / \mathrm{C}$ catalyst was selected for further investigation. Using a catalyst that is active at low temperatures decreases both the energy requirements for polyethylene processing and the thermodynamic driving force towards terminal C-C bond cleavage to produce $\mathrm{CH}_{4}$.

Based on these preliminary results, the hydrogenolysis of $n$ octadecane over $5 \mathrm{wt} \% \mathrm{Ru} / \mathrm{C}$ at $200^{\circ} \mathrm{C}$ was investigated as a function of time to track changes in the product distribution of $n$-alkanes with increasing conversion. As shown in Figure 1, the product distribution after $2 \mathrm{~h}$ includes $\mathrm{C}_{8}-\mathrm{C}_{17} n$-alkanes, and increasing the extent of reaction shifts the product distribution to lower molecular weights, implicating sequential cleavage events of both terminal and non-terminal C-C bonds. After $16 \mathrm{~h}, 100 \%$ of the $n$-octadecane was consumed and the products shifted from liquid-range alkanes to gaseous products in the $\mathrm{C}_{1}-\mathrm{C}_{6}$ range. Based on these data, we surmised the hydrogenolysis of longer-chain polyethylene over $\mathrm{Ru} / \mathrm{C}$ would also proceed via both terminal $\mathrm{C}-\mathrm{C}$ bond cleavage to produce $\mathrm{CH}_{4}$ and internal $\mathrm{C}-\mathrm{C}$ bond cleavage to produce shorter chain alkanes.

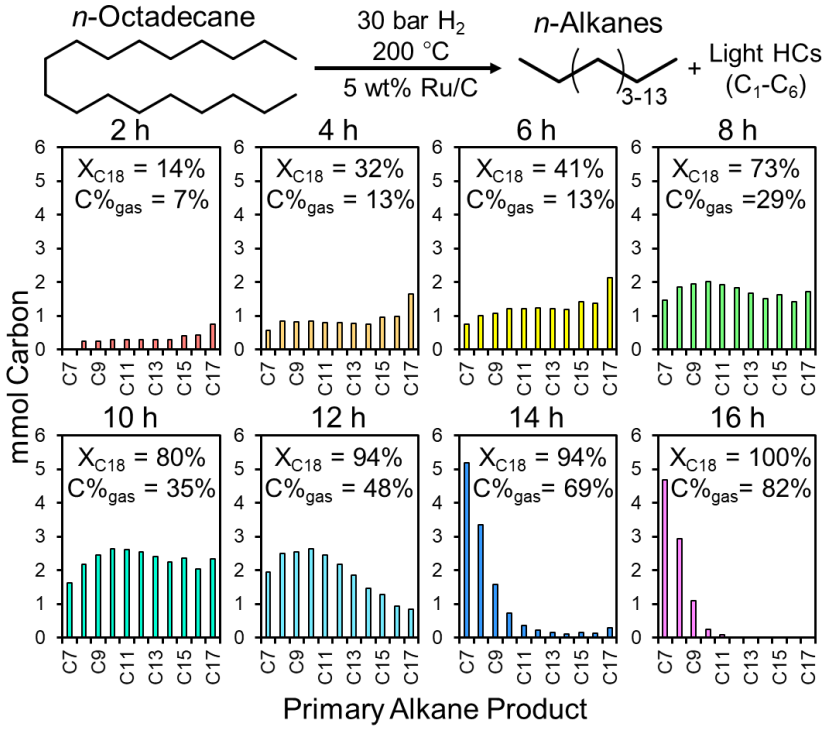

Figure 1: Hydrogenolysis of $n$-octadecane as a function of time over $5 \mathrm{wt} \% \mathrm{Ru} / \mathrm{C}$. Reaction conditions: $700 \mathrm{mg} n$-octadecane ( $\sim 50$ mmol carbon), $25 \mathrm{mg} 5 \mathrm{wt} \% \mathrm{Ru} / \mathrm{C}, 33$ bar $\mathrm{H}_{2}, 200^{\circ} \mathrm{C}$.

The effect of temperature and hydrogen pressure on the hydrogenolysis of model polyethylene (Sigma-Aldrich, average $\mathrm{M}_{\mathrm{w}}$ 4,000 , average $M_{n} 1,700$, Table S1) was investigated over $R u / C$ to identify suitable reaction conditions for the hydrogenolysis of realistic post-consumer polyethylene waste (Figure 2, Figure S4-S6). At all temperatures investigated between $200-250^{\circ} \mathrm{C}$ and using a 4:1 PE:catalyst mass ratio, polyethylene conversion reached $100 \%$ and generated exclusively gaseous products. At $200^{\circ} \mathrm{C}$, the head space contained mainly $\mathrm{CH}_{4}$, ethane, propane, and butane. Upon increasing the temperature to $225^{\circ} \mathrm{C}$, only $\mathrm{CH}_{4}$ and ethane were produced, and at $250^{\circ} \mathrm{C}$, the product yield was pure $\mathrm{CH}_{4}$ in near stoichiometric yields. The effect of hydrogen pressure on polyethylene hydrogenolysis products over $\mathrm{Ru} / \mathrm{C}$ at $200^{\circ} \mathrm{C}$ (using a $28: 1$ PE:catalyst mass ratio) is shown in Figure $\mathbf{2 b}$, with a more detailed compositional analysis shown in Figure 2c. At increasing hydrogen pressures, the yield of gas relative to liquid and solid increases, suggesting a sequence shifting from solid alkanes $\left(>\mathrm{C}_{45}\right)$ to solvated liquid alkanes $\left(\mathrm{C}_{8}-\mathrm{C}_{45}\right)$, and finally to light alkane gases $\left(\mathrm{C}_{1-}\right.$ $\mathrm{C}_{7}$ ). 

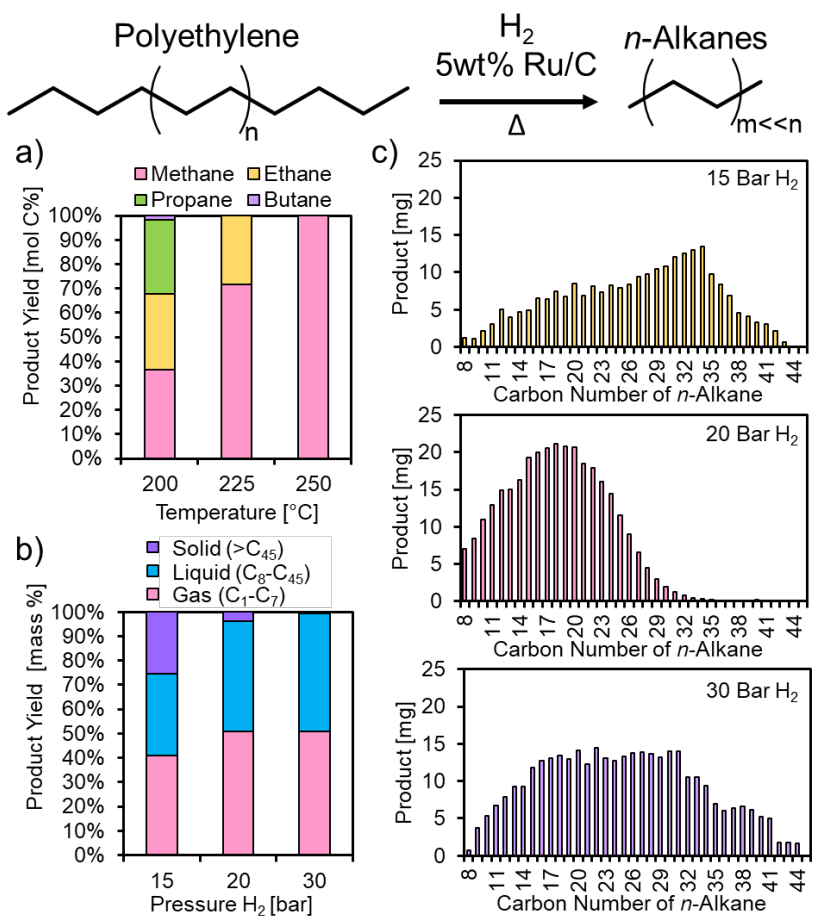

Figure 2: Optimizing reaction conditions for the hydrogenolysis of polyethylene (average $M_{w} 4,000$ ): a) Effect of temperature on over-

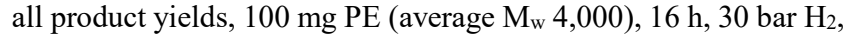
$25 \mathrm{mg} 5 \mathrm{wt} \% \mathrm{Ru} / \mathrm{C}, 200-250^{\circ} \mathrm{C}, 100 \%$ conversion, b) Effect of $\mathrm{H}_{2}$ pressure on overall product composition, $200^{\circ} \mathrm{C}, 16 \mathrm{~h}, 700 \mathrm{mg} \mathrm{PE}$ (average $\mathrm{M}_{\mathrm{w}} 4,000$ ), $25 \mathrm{mg} 5 \mathrm{wt} \% \mathrm{Ru} / \mathrm{C}, \mathrm{c}$ ) Liquid composition of $\mathrm{C}_{8}-\mathrm{C}_{45}$ products shown in $\mathrm{b}$.

Based on these data, we selected reaction conditions of 20 bar $\mathrm{H}_{2}, 200^{\circ} \mathrm{C}$ as optimal for producing a distribution of $n$-alkanes in the processible liquid range when using $700 \mathrm{mg}$ polyethylene and $25 \mathrm{mg}$ catalyst. Investigations of hydrogenolysis of Ir-based catalysts with both experiment and density functional theory (DFT) calculations have suggested that hydrogen inhibits hydrogenolysis rates, the extent of which is affected by the structure of the alkane due to changes in enthalpy and entropy of the transition state. ${ }^{23} \mathrm{~A}$ study of the mechanism of hydrogenolysis of light alkanes over $\mathrm{Ru} / \mathrm{CeO}_{2}$ also suggested that $\mathrm{H}_{2}$ pressure had a marked effect on selectivity for $\mathrm{C}-\mathrm{C}$ bond scission, where high $\mathrm{H}_{2}$ pressure is necessary to avoid $\mathrm{CH}_{4}$ formation. ${ }^{11}$ These opposing effects explain why an intermediate $\mathrm{H}_{2}$ pressure of 20 bar was ideal for achieving high selectivity to liquid-range $n$-alkanes in our experiments. As observed from both the model compound studies with $n$-octadecane and with polyethylene, the product distribution and selectivity for hydrogenolysis can be tuned by manipulating reaction temperature, $\mathrm{H}_{2}$ pressure, and residence time.

Implementation of hydrogenolysis technology for the catalytic upcycling of genuine post-consumer polyolefin waste will require flexibility in the molecular weight and composition of the feedstock, including extent of branching, moisture, and contaminants. To this end, we demonstrated the hydrogenolysis of two additional sources of polyethylene: low-density polyethylene (Aldrich, Table S2) with a melt index $25 \mathrm{~g} / 10 \mathrm{~min}\left(190^{\circ} \mathrm{C} / 2.16 \mathrm{~kg}\right)$, denoted here as LDPE MI25, and a post-consumer LDPE plastic bottle. The former is a material commonly used in toys, lids, and closures, ${ }^{24}$ and the latter was previously used as a solvent bottle containing water (VWR). The results from these reactions are summarized in Figure 3 and Figures S7-S13. The mass yields of liquid $\left(\mathrm{C}_{8}-\mathrm{C}_{45}\right)$ and gaseous $\left(\mathrm{C}_{1}-\mathrm{C}_{7}\right) n$-alkanes for three substrates are shown in Figure 3a. For each of these substrates, both liquid and gaseous products are obtained, while the gray represents the unaccounted products in the mass balance. Only gaseous and liquid products were observed for the reactions over polyethylene (average $\mathrm{M}_{\mathrm{w}} 4,000$, denoted PE $4 \mathrm{~K})$, LDPE MI25, or the LDPE plastic bottle. The gaseous product distributions for the three substrates are shown in Figure 3b, and the $\mathrm{C}_{8}-\mathrm{C}_{45}$ products are shown in Figure 3c-e for PE 4K, LDPE MI25, and the post-consumer LDPE plastic bottle, respectively. A small number of branched alkanes were also observed (Figure S10) over LDPE MI25, likely due to carbon chain branches in the substrate. While less substrate was used for the hydrogenolysis of the LDPE plastic bottle (200 mg) compared to the model polyethene $(1,400 \mathrm{mg})$, the formation of liquid products in spite of the higher complexity of this material and lack of any pre-treatment is promising, and indicates the feasibility of this method for the production of liquid products from post-consumer polyolefins. Furthermore, we observed that at longer reaction times $(16 \mathrm{~h})$ at $225^{\circ} \mathrm{C}$, the LDPE plastic bottle could be converted into $\mathrm{CH}_{4}$ with nearly $100 \%$ selectivity (Figure S13), which represents a promising avenue to produce natural gas from post-consumer plastic waste.
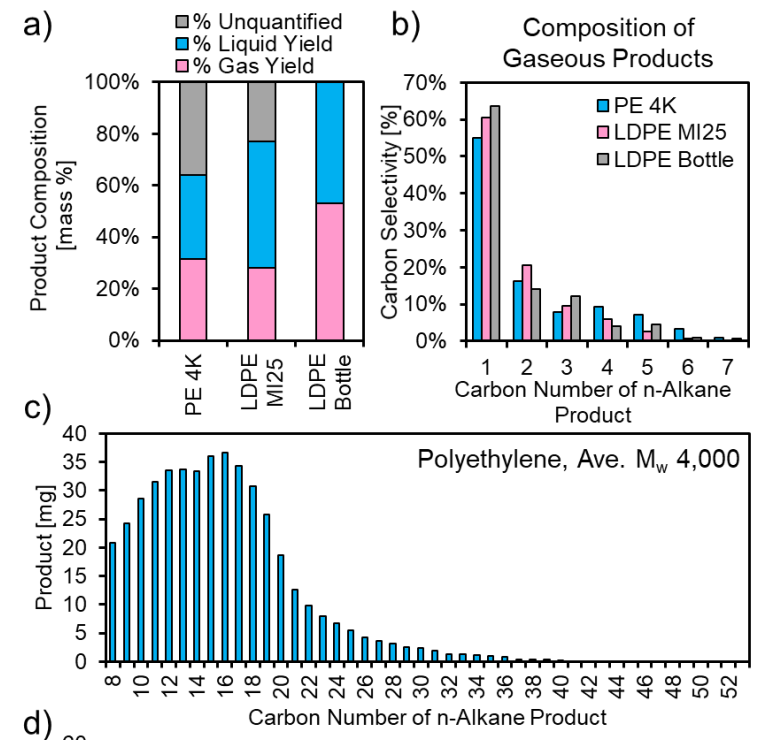

d)

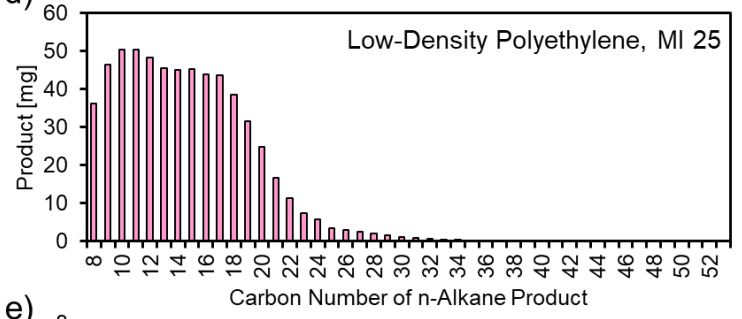

e)

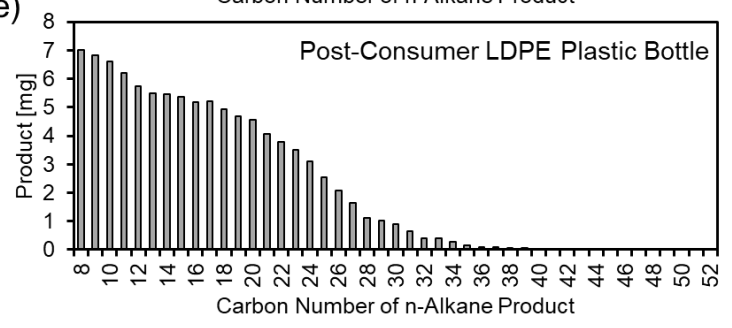

Figure 3: a) Product distributions for polyethylene hydrogenolysis over $5 \mathrm{wt} \% \mathrm{Ru} / \mathrm{C}$ with $\mathrm{PE} 4 \mathrm{~K}\left(200^{\circ} \mathrm{C}, 1.4 \mathrm{~g}\right.$ PE $4 \mathrm{~K}, 56 \mathrm{mg} 5 \mathrm{wt} \%$ $\mathrm{Ru} / \mathrm{C}, 22$ bar $\left.\mathrm{H}_{2}, 16 \mathrm{~h}\right)$, LDPE MI25 $\left(225^{\circ} \mathrm{C}, 1.4 \mathrm{~g}\right.$ LDPE, $50 \mathrm{mg} 5$ wt $\% \mathrm{Ru} / \mathrm{C}, 22$ bar $\mathrm{H}_{2}, 16 \mathrm{~h}$ ), and a post-consumer LDPE plastic bottle $\left(225^{\circ} \mathrm{C}, 200 \mathrm{mg}\right.$ LDPE, $\left.25 \mathrm{mg} 5 \mathrm{wt} \% \mathrm{Ru} / \mathrm{C}, 22 \mathrm{bar} \mathrm{H}_{2}, 2 \mathrm{~h}\right)$; b) gaseous product distribution for PE $4 \mathrm{~K}$, LDPE MI25, and LDPE plastic bottle; c) $\mathrm{C}_{8}-\mathrm{C}_{45}$ - product distribution for $\mathrm{PE} 4 \mathrm{~K}$; d) $\mathrm{C}_{8}-\mathrm{C}_{45}+$ product distribution for LDPE MI25, e) $\mathrm{C}_{8}-\mathrm{C}_{45}+$ product distribution for LDPE plastic bottle. 
In this work, we have demonstrated that Ru-based catalysts are active for the hydrogenolysis of polyethylene under mild conditions to produce processible liquid alkanes. Temperature, hydrogen pressure, and reaction time can all be manipulated to control product distribution and selectivity, enabling the production of liquid products or complete hydrogenolysis to pure $\mathrm{CH}_{4}$. The identification of Ru-based materials as a class of heterogeneous catalysts for the efficient depolymerization of polyethylene into liquid alkanes, or pure $\mathrm{CH}_{4}$ compatible with existing natural-gas infrastructure, opens doors for future investigations into improving reactivity, understanding selectivity, and exploration of a variety of feedstocks and compositions. Further studies involving the effects of substrate branching, reactivity and characterization of other hydrocarbon polymers such as polypropylene and polystyrene, mechanistic interrogation of active site requirements for selective internal $\mathrm{C}-\mathrm{C}$ bond cleavage, models for predicting distributions of $\mathrm{C}-\mathrm{C}$ bond cleavage, utilization of experimentally-determined kinetic parameters to inform cleavage probability at various locations along the carbon chain, characterization of the $\mathrm{Ru}$ catalyst surface and mass transfer in the polymer melt, and technoeconomic analysis of the process, are currently underway in our laboratory.

With heterogeneous catalysts, additional parameters for exploration include utilizing tailored acid or acid-base supports to promote tandem isomerization and hydrogenolysis, zeolites and microporous materials to impose confinement effects, and the synthesis of bi-metallic catalysts to improve selectivity, activity, and stability, and to control $\mathrm{C}-\mathrm{O}, \mathrm{C}-\mathrm{C}$, and $\mathrm{C}=\mathrm{C}$ bond scission in mixed plastics feeds. Exhaustive studies into the effects of moisture and contaminants, ${ }^{25}$ as well as engineering creative systems of product removal, will be critical for the industrialization of this reaction, enabling the integration of polyolefin upcycling technology into the global economy, and ultimately providing an economic incentive for the removal of waste plastics from the landfill and environment.

\section{ASSOCIATED CONTENT}

\section{Supporting Information}

Materials and Methods (Fig. S1, Table S1-S2), Catalyst Characterization (Fig. S2-S3, Table S3), Product Characterization (GC-MS, GC-FID, GC-MS, Supporting Images, Fig. S4-S13) (PDF).

\section{AUTHOR INFORMATION}

\section{Corresponding Author \\ yroman@mit.edu}

\section{ACKNOWLEDGMENT}

Funding was provided by the US Department of Energy, Office of Energy Efficiency and Renewable Energy, Advanced Manufacturing Office (AMO) and Bioenergy Technologies Office (BETO). This work was performed as part of the Bio-Optimized Technologies to keep Thermoplastics out of Landfills and the Environment (BOTTLE) Consortium and was supported by AMO and BETO under contract no. DE-AC36-08GO28308 with the National Renewable Energy Laboratory (NREL), operated by Alliance for Sustainable Energy, LLC. The BOTTLE Consortium includes members from MIT, funded under contract no. DE-AC36-08GO28308 with NREL. The authors thank Sujay Bagi for assistance with Transmission Electron Microscopy.

\section{REFERENCES}

1. Geyer, R.; Jambeck, J. R.; Law, K. L., Production, use, and fate of all plastics ever made. Science Advances 2017, 3 (7), e1700782.

2. Hong, M.; Chen, E. Y. X., Future Directions for Sustainable Polymers. Trends in Chemistry 2019, 1 (2), 148-151.
3. Chemical Economics Handbook (CEH): Plastics Recycling; IHS Markit: 2020.

4. Al-Salem, S. M.; Lettieri, P.; Baeyens, J., Recycling and recovery routes of plastic solid waste (PSW): A review. Waste Management 2009, 29 (10), 2625-2643.

5. Andrady, A. L., Microplastics in the marine environment. Marine Pollution Bulletin 2011, 62, 1596-1605.

6. Serrano, D. P.; Aguado, J.; Escola, J. M., Developing Advanced Catalysts for the Conversion of Polyolefinic Waste Plastics into Fuels and Chemicals. ACS Catalysis 2012, 2 (9), 1924-1941.

7. Anuar Sharuddin, S. D.; Abnisa, F.; Wan Daud, W. M. A.; Aroua, M. K., A review on pyrolysis of plastic wastes. Energy Conversion and Management 2016, 115, 308-326.

8. Kunwar, B.; Cheng, H. N.; Chandrashekaran, S. R.; Sharma, B. K., Plastics to fuel: a review. Renewable and Sustainable Energy Reviews 2016, 54, 421-428.

9. Bond, G. C.; Rajaram, R. R.; Burch, R., Hydrogenolysis of Propane, n-Butane, and Isobutane over Variously Pretreated Ru/TI02 Catalysts. The Journal of Physical Chemistry 1986, 90, 4877-4881.

10. Bond, G. C.; Yide, X., Effect of Reduction and Oxidation on the Activity of Ruthenium/Titania Catalysts for n- Butane Hydrogenolysis. Journal of the Chemical Society, Chemical Communications 1983, 1248-1249.

11. Nakagawa, Y.; Oya, S. I.; Kanno, D.; Nakaji, Y.; Tamura, M.; Tomishige, K., Regioselectivity and Reaction Mechanism of RuCatalyzed Hydrogenolysis of Squalane and Model Alkanes. ChemSusChem 2017, 10 (1), 189-198.

12. Flaherty, D. W.; Hibbitts, D. D.; Iglesia, E., Metal-Catalyzed C-C Bond Cleavage in Alkanes: Effects of Methyl Substitution on Transition-State Structures and Stability. Journal of the American Chemical Society 2014, 136 (27), 9664-76.

13. Egawa, C.; Iwasawa, Y., Ethane hydrogenolysis on a $\mathrm{Ru}(1,1,10)$ surface. Surface Science 1988, 198 (1), L329-L334.

14. Kempling, J. C.; Anderson, R. B., Hydrogenolysis of n-Butane on Supported Ruthenium. Industrial \& Engineering Chemistry Process Design and Development 190, 9 (1), 116-120.

15. Dong, L.; Lin, L.; Han, X.; Si, X.; Liu, X.; Guo, Y.; Lu, F.; Rudić, S.; Parker, S. F.; Yang, S.; Wang, Y., Breaking the Limit of Lignin Monomer Production via Cleavage of Interunit Carbon-Carbon Linkages. Chem 2019, 5 (6), 1521-1536.

16. Xiao, L.-P.; Wang, S.; Li, H.; Li, Z.; Shi, Z.-J.; Xiao, L.; Sun, R.-C.; Fang, Y.; Song, G., Catalytic Hydrogenolysis of Lignins into Phenolic Compounds over Carbon Nanotube Supported Molybdenum Oxide. ACS Catalysis 2017, 7 (11), 7535-7542.

17. Dufaud, V.; Basset, J.-M., Catalytic Hydrogenolysis at Low Temperature and Pressure of Polyethylene and Polypropylene to Diesels or Lower Alkanes by a Zirconium Hydride Supported on Silica-Alumina: A Step Toward Polyolefin Degradation by the Microscopic Reverse of Ziegler \pm Natta Polymerization. Angewandte Chemie International Edition 1998, 37 (6), 806-810.

18. Celik, G.; Kennedy, R. M.; Hackler, R. A.; Ferrandon, M.; Tennakoon, A.; Patnaik, S.; LaPointe, A. M.; Ammal, S. C.; Heyden, A.; Perras, F. A.; Pruski, M.; Scott, S. L.; Poeppelmeier, K. R.; Sadow, A. D.; Delferro, M., Upcycling Single-Use Polyethylene into HighQuality Liquid Products. ACS Central Science 2019, 5 (11), 17951803.

19. Hong, M.; Chen, E. Y., Towards Truly Sustainable Polymers: A Metal-Free Recyclable Polyester from Biorenewable Non-Strained gamma-Butyrolactone. Angewandte Chemie International Edition 2016, 55 (13), 4188-93.

20. Hu, Y.; Jiang, G.; Xu, G.; Mu, X., Hydrogenolysis of lignin model compounds into aromatics with bimetallic Ru-Ni supported onto nitrogen-doped activated carbon catalyst. Molecular Catalysis 2018, $445,316-326$.

21. Li, T.; Lin, H.; Ouyang, X.; Qiu, X.; Wan, Z., In Situ Preparation of $\mathrm{Ru} @ \mathrm{~N}$-Doped Carbon Catalyst for the Hydrogenolysis of Lignin To Produce Aromatic Monomers. ACS Catalysis 2019, 9 (7), 5828-5836.

22. Manish Shetty, K. M., Teerawit Prasomsri, William H. Green, Yuriy Román-Leshkov, Reactivity and stability investigation of supported molybdenum oxide catalysts for the hydrodeoxygenation (HDO) of m-cresol. Journal of Catalysis 2015, 331, 86-97.

23. Hibbitts, D. D.; Flaherty, D. W.; Iglesia, E., Effects of Chain Length on the Mechanism and Rates of Metal-Catalyzed Hydrogenolysis of n-Alkanes. The Journal of Physical Chemistry C 2016, 120 (15), 8125-8138. 
24. DOW LDPE 993I Low Density Polyethylene Resin; The Dow Chemical Company: 8-30-2011, 2011.
25. Ragaert, K.; Delva, L.; Van Geem, K., Mechanical and chemical recycling of solid plastic waste. Waste Management 2017, 69, 24-58. 
Single-Use Polyethylene

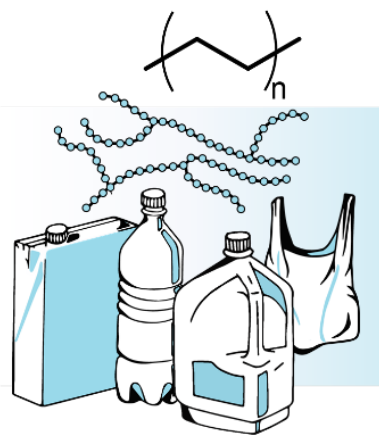

High-Value Liquid Alkanes

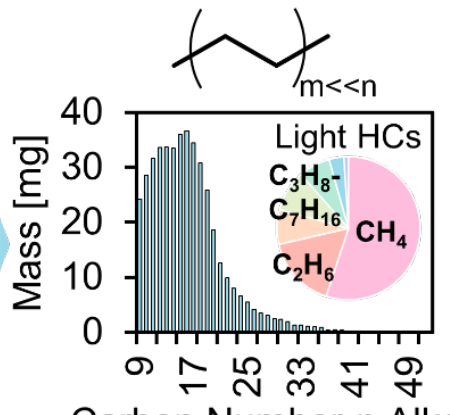

Carbon Number $n$-Alkane 